\title{
A Study of Business English (ESP) Learning Anxiety from the Perspective of Ecology
}

\author{
Zhaojun Chen, Miao Huang \\ Foreign Language Teaching Department, Yantai Nanshan University, Yantai, China \\ Email: chenzhaojun1980@126.com, irenehashida@126.com
}

Received 1 April 2016; accepted 3 June 2016; published 6 June 2016

Copyright (C) 2016 by authors and Scientific Research Publishing Inc.

This work is licensed under the Creative Commons Attribution International License (CC BY). http://creativecommons.org/licenses/by/4.0/

c) (i) Open Access

\begin{abstract}
Business English (BE) language characteristics and many classroom teaching factors contribute to the anxiety of BE learning. The ecology can be put in use into BE teaching to make the ecological classroom. This research is taken to show relations between the ecological classroom teaching of BE (BEECT) and BE learning anxiety (BELA). The findings are as followed: 1) BEECT is in good order and students' BELA is to the intermediate degree; 2) BELA has the generally negative correlation to students' general English proficiency; 3) BEECT has the higher negative correlation to BELA, and they are significantly linearly dependent; 4) as to BELA, significant statistical differences exist between high score group and low score group in the classroom learning efficiency, the teacherstudent affective intercommunication, and student-student intercommunication. In order to lower BELA, BE teachers are suggested cultivating learners' academic English proficiency, strengthening learners' ambiguity tolerance, and using ecologically multimodal discourses.
\end{abstract}

\section{Keywords}

ESP, Business English, Ecology, Ecological Classroom, Learning Anxiety

\section{Introduction}

Business English is a branch of English for Specific Purposes (ESP). At present, in China, English for General Purposes (EGP) and ESP coexist in college English teaching system (Wen, 2014: pp. 1-8). To establish a diversified, characterized, personalized and localized college English curriculum system based on comprehensive English, with ESP as the main development direction of diversification, accords with the training objective of multilayer talents, in line with the actual conditions of foreign language education, and with the urgent needs of social, economic, and cultural development (Ding \& Dai, 2013: pp. 17-23).

During the development history of linguistics, it has a close relation with philosophy, psychology and natural 
science and social science, etc.

Following the structuralism, behaviorism, cognitive psychology and constructivism theories, ecological linguistics, also known as the ecology of language, emerges as a new linguistic school, integrating research results of ecology and linguistics (Wang \& Jia, 2011: pp. 3-6). Ecological theories have had a profound impact on the language teaching (Wu, 2011: pp. 111-122), emphasizing the interactive process of the learners' knowledge and experience with the outside world (Wang \& Jia, 2011: pp. 3-6).

In the 21st century, the ecological classroom teaching of foreign languages has gradually been approved and it is conducive to maintaining the exuberant vitality of foreign language classroom teaching (Wang \& Jia, 2011: pp. 3-6). The ecological classroom teaching promotes students' learning motivation (Leather \& Dam, 2003), and conforms to the students' individual needs and is agreeable with teachers and students (Guo, 2013: pp. 99-106). The ecologicalized teaching environment is a direction of the development of the foreign language teaching (Chen \& Gu, 2008: pp. 3-8). Likewise, ESP teaching environment should be ecological (Gu, 2012: pp. 47-59).

Chinese scholars carried out some researches on ESP learning anxiety. Huang \& Zou (2010: pp. 166-167) made an investigation about the anxiety in learning English for geographic information system (GIS). Gao et al. (2010: pp. 138-140) and Shi (2012: p. 225) studied medical English learning anxiety. Sun \& Wang (2013: pp. 90-91) explored the anxiety in ESP oral expression. Shi (2014: pp. 141-143) gave a comparative study of the anxiety between ESP and EGP learning. On their bases, this study, from a new perspective, is to discuss the BE learning anxiety in the ecological environment of classroom. It is guided by the following research questions.

1) To what extent are BEECT and students' BELA in BEECT?

2) What are the relationships between BEECT factors and BELA?

3) How different is BELA behaved by students in high score group (HSG) from those in low score group (LSG)?

\section{Literature Review of the Ecological Classroom Teaching of Business English (BEECT) and Business English Learning Anxiety (BELA)}

\subsection{Ecological Classroom Teaching of Business English (BEECT)}

ESP is a subsystem of language ecology system, in which professionalism is characteristic of ESP ecosystem, the communicative nature reflects the dependence on the environment, and learners' needs embody the ecological subjects (Wu, 2014: pp. 283-284).

With the perspective of ecology in foreign language teaching, it is based on the principle of ecology to investigate the interaction and co-adaptation between internal elements of the teaching system and the surrounding environment, to study various teaching phenomena, such as imbalance phenomenon, and their causes, and to probe into the features and functions of foreign language teaching ecology and its basic law of evolution and development (Chen, 2010). In that way, BEECT is a special kind of ecology, and has unique ecological subjects (Business English teachers and learners), with the interaction and interrelation of teachers, learners and classroom environments into the organic whole. BEECT is in the harmonious atmosphere and multi-dimensional interaction, respects differences, and is full of competition and cooperation.

\subsection{Business English Learning Anxiety (BELA)}

Horwitz et al. (1986: p. 128) defined foreign language anxiety is as "a distinct complex of self-perceptions, beliefs, feelings, and behaviors related to classroom language learning arising from the uniqueness of the language learning process".

According to their foreign language classroom anxiety scale (FLCAS), business English learning anxiety is associated with communication apprehension (item 1, 3, 4, 9, 13, 14, 18, 20, 24, 27, 29, 33), test anxiety(item 8, 10, 21), fear of negative evaluation (item 2, 7, 15, 19, 23, 31), and general fear of BE classes (item 5, 6, 11, 12, $16,17,22,25,26,28,30,32)$.

$\mathrm{BE}$, as one variety of ESP, has its special linguistic features. There are a large number of technical terms in $\mathrm{BE}$ which have accurate but relatively narrow meanings different from those in EGP. What is more, BE vocabularies are characterized by nominalization. Learners may be unfamiliar with old words and uncertain of new words. Moreover, hedges are used in BE communications based on theories of conversational implicature, co-operative principles and politeness principles. These features may directly lead to learners' anxiety, and cause 
mental tension or fear, which influence and hinder ESP learning (Shi, 2014: pp. 141-143). These features also bring in tolerance of ambiguity of language (TAL), which, as an important factor of individual difference, also affects learners' BE learning proficiency. As Lei (2011) pointed out, during the process of learning, the learners may confront a lot of ambiguous, unfamiliar or uncertain situations. Learners with different level of TAL may have different attitudes. Learners who have higher level of TAL tend to cope with the ambiguities more easily and they can achieve a better performance in language learning. While learners with lower level of TAL may feel nervous or anxious when they are confronting ambiguities, and they are tend to have poorer performance in language learning. TAL is also true of the process of BE learning. TAL has a negative correlation with BE learning anxiety. Generally speaking, the higher the level of TAL is, the lower the level of anxiety is.

\section{Methodology}

\subsection{Subjects and Instruments}

In June 2015, a sample of 60 junior students of Business English major from East China Institute of Technology, participated in the study. Their ages range from 20 to 23, the mean age is 21, and female students account for 83\%. They were asked to complete the Business English Learning Anxiety Scale (BELAS) and the Questionnaire of Ecological Classroom Teaching of BE (QBEECT). 60 students' data were effectively adopted for statistical analysis. BELAS is adapted on the basis of Horwitz's FLCAS. QBEECT is based on the questionnaire of ecological environment of College English teaching (Chen \& Shan, 2008: pp. 96-100). Classroom learning efficiency (CLE) consists of item 1, 2, 3, 4, 5; teacher-student interaction (TSI), 6, 7, 8, 9, 10, 11, 12; student-student intercommunication (SSI), 13, 14, 15, 16, 17, 18, 19, 20; teacher-student affective intercommunication (TSAI), 21, 22, 23, 24, 25, 26, 27; students' cognition of learning (SCL), 28, 29. The students are asked to show their opinions in terms of a five-point scale:

$1=$ "This statement is almost never true of me"

2 = "This statement is usually not true of me"

$3=$ "This statement is sometimes true of me"

$4=$ "This statement is usually true of me"

5 = "This statement is almost always true of me"

Student's TEM4 scores are used as the examination of their general English proficiency.

\subsection{Data Analysis}

All the data were computerized by means of SPSS13.0. Internal consistence reliability was calculated for the instruments. The overall Cronbach's alpha reliability for BELAS was 0.933, and QBEECT0.871, which showed the reliability of the questionnaires convincingly (see Table 1 ).

The quantitative analysis involved several statistical procedures:

1) Descriptive statistics were computed to summarize the students' responses to BEECT and BELA;

2) Pearson correlations analysis was conducted to examine the relationship between BELA and students' general

\begin{tabular}{|c|c|c|c|}
\hline Questionnaires & Factors & Amount & Cronbach Alpha \\
\hline \multirow{4}{*}{ BELAS } & Communication apprehension (CA) & 12 & \multirow{4}{*}{0.933} \\
\hline & Fear of negative evaluation (FNE) & 6 & \\
\hline & Test anxiety (TA) & 3 & \\
\hline & General fear of BE classes (GA) & 12 & \\
\hline \multirow{5}{*}{ QBEECT } & Classroom learning efficiency (CLE) & 5 & \multirow{5}{*}{0.871} \\
\hline & Teacher-student interaction (TSI) & 7 & \\
\hline & Student-student intercommunication (SSI) & 8 & \\
\hline & Teacher-student affective intercommunication (TSAI) & 7 & \\
\hline & Students' cognition of learning (SCL) & 2 & \\
\hline
\end{tabular}


English proficiency, and the relationship between BEECT and BELA; multiple regression analysis was used to determine the predictive power of BEECT over BELA;

3) Independent samples t-tests were carried out to check the differences between HSG (top 25\% of subjects in BELA) and LSG (bottom 25\% of subjects in BELA).

\section{Results and Discussions}

The questionnaires are the five-point Likert scale. The higher marks students score, the more frequently they behave. The frequency is divided into three levels—-high (Mean Score 3.5 - 5.0), medium (Mean Score 2.5 - 3.4) and low (Mean Score 1.0 - 2.4) as shown in Table 2.

The correlations between different variables are: positive correlation, negative correlation and zero/no correlation. Positive correlation indicates if variable A is increasing, variable B is increasing accordingly. Negative correlation means if variable A is increasing, variable B is decreasing. Zero or no correlation shows that no regularity can be drawn from the two variables. The degree of correlation is usually evaluated by Pearson Product Moment of Correlation Coefficient (r), which is between -1.0 to +1.0 as Table 3 shows. Generally, there are three kinds of levels $\left({ }^{* * *} p<0.001,{ }^{* *} p<0.01\right.$, and $\left.{ }^{*} p<0.05\right)$ at which correlation is significant. ${ }^{* *} p<0.001$ or $p=$ 0.000 means there is only $0.1 \%$ error, which shows variable A is most significantly correlated to variable $\mathrm{B} ;{ }^{* *} p<$ 0.01 or $p=0.01$ means there is only $1 \%$ error, which shows variable $\mathrm{A}$ is more significantly correlated to variable $\mathrm{B} ;{ }^{*} p<0.05$ or $p=0.05$ means there is only $5 \%$ error, which shows variable A is much significantly correlated to variable $B$; only if $p$ value is less than 0.05 , correlation coefficient (r) is statistically significant or meaningful.

\subsection{Analysis of BEECT}

\section{Overall Frequency of BEECT}

According to Table 4, in BE classroom, students have high-level cognition of learning; the affective intercourse between the teacher and students is to the high degree; the intercommunication among students, teacher-student interaction, and students' learning efficiency are at the medium level. In Table 5, the factor about students' cognition of learning has little significant correlation with the other four factors among which there is moderately significant correlation to one another. Therefore, BEECT is in good condition.

To be specific and prominent, concerning SCL, students have highly recognized that only if passively learning is transformed into initiatively learning, they would achieve the life-long learning capability.

Table 2. Frequency scale.

\begin{tabular}{ccc}
\hline Mean Score & Frequency & Degree \\
\hline $4.5-5.0$ & High & Almost always \\
$3.5-4.4$ & Oedium & Sometimes \\
$2.5-3.4$ & Low & Seldom \\
$1.5-2.4$ & & Almost never \\
\hline
\end{tabular}

Table 3. Pearson product moment of correlation coefficient (r).

\begin{tabular}{cc}
\hline Correlation Coefficient (r) & Degree of Correlation \\
\hline $0.90- \pm 1.0$ & Highly significant \\
$\pm 0.70- \pm 0.90$ & Obviously significant \\
$\pm 0.40- \pm 0.70$ & Moderately significant \\
$\pm 0.20- \pm 0.40$ & Lowerally significant \\
$< \pm 0.20$ & Lignificant or ignorable
\end{tabular}


Table 4. BEECT variables.

\begin{tabular}{cc}
\hline BEECT factors & Mean \\
\hline Students' cognition of learning (SCL) & 4.07 \\
Teacher-student affective intercommunication (TSAI) & 4.00 \\
Student-student intercommunication (SSI) & 3.44 \\
Teacher-student interaction (TSI) & 3.38 \\
Classroom learning efficiency (CLE) & 3.28 \\
\hline
\end{tabular}

Table 5. Correlations between BEECT factors.

\begin{tabular}{ccccccc}
\hline \multirow{2}{*}{ Correlations between BEECT Factors } & CLE & TSI & SSI & TSAI & SCL \\
\hline \multirow{2}{*}{ Overall BEECT } & Pearson Correlation & 0.697 & 0.737 & 0.827 & 0.800 & 0.335 \\
& Sig. (2-tailed) & 0.000 & 0.000 & 0.000 & 0.000 & 0.009 \\
CLE & Pearson Correlation & 1 & 0.344 & 0.433 & 0.462 & 0.157 \\
& Sig. (2-tailed) & & 0.007 & 0.001 & 0.000 & 0.232 \\
TSI & Pearson Correlation & 0.344 & 1 & 0.522 & 0.458 & 0.180 \\
& Sig. (2-tailed) & 0.007 & & 0.000 & 0.000 & 0.169 \\
SSI & Pearson Correlation & 0.433 & 0.522 & 1 & 0.524 & 0.169 \\
& Sig. (2-tailed) & 0.001 & 0.000 & & 0.000 & 0.197 \\
TSAI & Pearson Correlation & 0.462 & 0.458 & 0.524 & 1 & 0.255 \\
& Sig. (2-tailed) & 0.000 & 0.000 & 0.000 & & 0.050 \\
SCL & Pearson Correlation & 0.157 & 0.180 & 0.169 & 0.255 & 1 \\
& Sig. (2-tailed) & 0.232 & 0.169 & 0.197 & 0.050 & \\
\hline
\end{tabular}

As for TSAI, the teacher has the strong love and patience of students, maintains the surrounding with peace and friendship with students, gives good care to students, fully respects students, and stimulates students' interest in learning. Besides, the teacher often communicates with students after class, such as how to conduct oneself, and students get useful advice and help. Therefore, the harmonious relationship between the teacher and students is highly better established.

In regard to SSI, students are more likely to cherish the time and opportunities communication of business English knowledge. In TSI, the teacher seldom buckets knowledge. Instead, in BE classroom, the group discussion is regularly carried out, in which whether students' learning achievement is good or not, all students are treated equally without partiality, and offered the similar opportunity to perform. The teacher-student cooperation degree is higher, and the classroom atmosphere is favorable and harmonious. In CLE, students are usually willing to learn $\mathrm{BE}$ autonomously, feel little anxious, participate in the classroom activities and master the content of BE course.

\subsection{Analysis of BELA}

\subsubsection{Analysis of BELA Variables}

The total score of 33 items of BELAS is the anxiety index from 33 to 165, with higher scores indicating more anxiety.

In terms of Table 6 and Figure 1, CA, FNE, TA, and GA are all to the moderate degree. The overall anxiety is to the same degree, basically presenting the normal distribution.

On the basis of Table 7, CA, FNE, TA, and GA are positively significantly correlated with the overall anxiety ( $r>0.7, p<0.01$ ), and so is the correlations between BELA four variables $(r>0.6, p<0.01)$, among which the correlation between CA and FNE is obviously significant $(\mathrm{r}>0.7, p<0.01)$.

Generally speaking, the relationship between anxiety degree and learning efficiency is presented by inverted 
Table 6. BELA variables.

\begin{tabular}{cccccc}
\hline Anxiety score & $\begin{array}{c}\text { Overall anxiety } \\
(\mathrm{OA})\end{array}$ & $\begin{array}{c}\text { Communication } \\
\text { apprehension (CA) }\end{array}$ & $\begin{array}{c}\text { Fear of negative } \\
\text { evaluation (FNE) }\end{array}$ & $\begin{array}{c}\text { Test } \\
\text { anxiety (TA) }\end{array}$ & $\begin{array}{c}\text { General fear } \\
\text { (GA) }\end{array}$ \\
\hline Mean & 92.27 & 33.97 & 15.87 & 8.35 & 34.08 \\
Minimum & 50.00 & 17.00 & 6.00 & 4.00 & 17.00 \\
Maximum & 142.00 & 52.00 & 27.00 & 14.00 & 58.00 \\
\hline
\end{tabular}

Table 7. Correlations between BELA variables.

\begin{tabular}{|c|c|c|c|c|c|c|}
\hline & BELA Variables & $\mathrm{OA}$ & CA & FNE & $\mathrm{TA}$ & GA \\
\hline \multirow{2}{*}{ OA } & Pearson Correlation & 1 & 0.925 & 0.885 & 0.742 & 0.913 \\
\hline & Sig. (2-tailed) & & 0.000 & 0.000 & 0.000 & 0.000 \\
\hline \multirow{2}{*}{ CA } & Pearson Correlation & 0.925 & 1 & 0.786 & 0.606 & 0.741 \\
\hline & Sig. (2-tailed) & 0.000 & & 0.000 & 0.000 & 0.000 \\
\hline \multirow{2}{*}{ FNE } & Pearson Correlation & 0.885 & 0.786 & 1 & 0.664 & 0.719 \\
\hline & Sig. (2-tailed) & 0.000 & 0.000 & & 0.000 & 0.000 \\
\hline \multirow{2}{*}{$\mathrm{TA}$} & Pearson Correlation & 0.742 & 0.606 & 0.664 & 1 & 0.637 \\
\hline & Sig. (2-tailed) & 0.000 & 0.000 & 0.000 & & 0.000 \\
\hline \multirow{2}{*}{ GA } & Pearson Correlation & 0.913 & 0.741 & 0.719 & 0.637 & 1 \\
\hline & Sig. (2-tailed) & 0.000 & 0.000 & 0.000 & 0.000 & \\
\hline
\end{tabular}

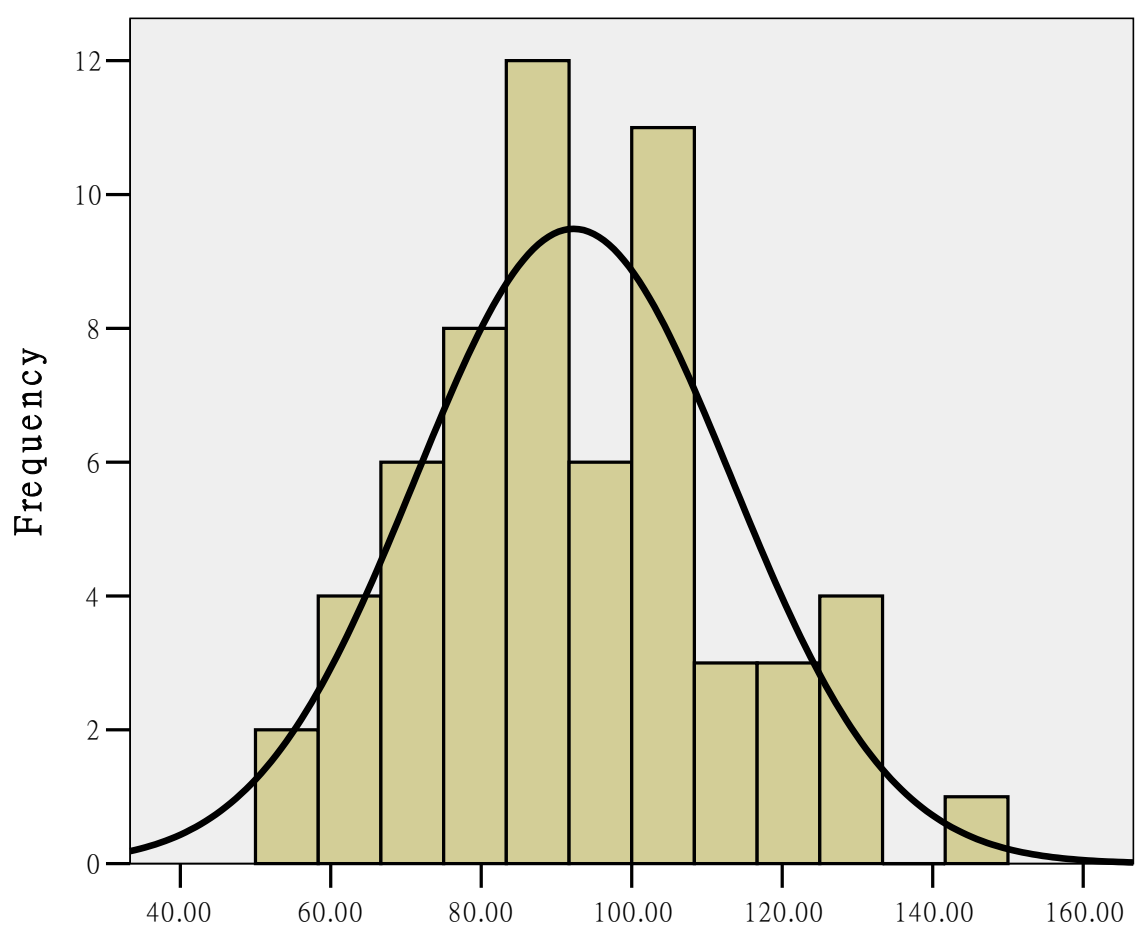

Figure 1. Histogram for BELA.

“U” curve. Namely, both high and low anxiety degree will reduce learning efficiency, while only medium degree can lead to the highest level of learning efficiency. A harmonious learning atmosphere can stimulate more facilitating anxiety and decrease debilitating anxiety, the former of which can promote the language learning course 
and the latter inhibit it (Ellis, 1994: pp. 34-35).

In general fear of BE classes, it wouldn't bother the students at all to take more BE classes and they feel at ease and acceptable in learning professional vocabulary, grammar and passages in BE. All they feel on their way to $\mathrm{BE}$ is very sure and relaxed.

In the respect of communication apprehension, without trembling, Students have great confidence in speaking in English in BE classes, which indicates strong control in their own psychology. Sometimes, students are panic and nervous in answering questions, which only indicates their concerns to the knowledge and is beneficial to their further thinking and exploration.

In the respect of negative evaluation, students don't worry about being laughed at by others, when discussing business knowledge in English. By contrary, it is the point of admiration, as fluency in speaking English is symbolic of education and self-cultivation and the concrete infestation of learning strategies. Meanwhile, ecological classroom environment also requires mutual respect between teachers and students. Sometimes, When the BE teacher correct their mistakes in English, the students will feel troubled, but rarely frightened. Trouble will make the learner to take their utmost effort to understand the English correction, which is in favor of BE learning. As for the teachers, they should correct students' mistakes properly with the purpose of making themselves understood by every possible means, in bilingual teaching, if necessary.

In the respect of test anxiety, students are usually worried about their failing in BE courses, which has close relationship with their graduation certificate. Diploma strategy is the most intense and unavoidable phenomenon among college students, which reflects the lowest level of safety needs and higher needs. The test anxiety is the temporary response to curriculum evaluation and not specific to the foreign language teaching. In practice, both the student and teachers should first try their best to meet the students' lower level need in safety; Then teachers should raise their professional ethics and competence and students promote their inner learning motivation so as to form facilitating anxiety, build harmonious teacher-student relationship, and promote classroom teaching quality. Finally, the students can realize their individual and social value by sublimating the lower level of needs to the higher level of personal realization.

\subsubsection{The Relationship between EGP Proficiency and BELA}

Based on Table 8, students' EGP proficiency (represented by TEM4 Score) and BELA are generally negatively correlated ( $r=-0.25, p=0.05$ ), which shows that the more proficient students' EGP is, the lower the anxiety is during students' learning BE. The two variables-FNE $(\mathrm{r}=-0.35, p=0.01)$ and TA $(\mathrm{r}=-0.36, p=0.01)$ are also generally negatively correlated to students' EGP proficiency. Specifically, the more proficient students' EGP is, the less degree of their FNE and TA in BE classroom.

The empirical study of Kong (2012: pp. 74-78) indicates that EGP teaching and ESP teaching should be necessarily integrated, on account of the coordination relation between EGP and ESP that are different components of one linguistic continuum. ESP knowledge acquisition is attributed to students' continuous processing of the implicit learning of EGP. The synergistic effect of the implicit and explicit learning is the important prerequisite

\section{Table 8. Correlations between BELA variables and TEM4 score.}

\begin{tabular}{ccc}
\hline & BELA Variables & TEM4 score \\
\hline OA & Pearson Correlation & -0.25 \\
& Sig. (2-tailed) & 0.05 \\
CA & Pearson Correlation & -0.17 \\
& Sig. (2-tailed) & 0.12 \\
FNE & Pearson Correlation & -0.35 \\
TA & Sig. (2-tailed) & 0.01 \\
& Pearson Correlation & -0.36 \\
GA & Sig. (2-tailed) & 0.01 \\
\hline
\end{tabular}


to the improvement of ESP course teaching quality, which is the reason why EGP is attached great importance to in BE teaching. EGP is favorable for students to enhance the capacity of self-monitoring and self-repair on the input and output of BE knowledge, and to heighten the accuracy and appropriacy of BE knowledge application, accompanied by the consolidation of EGP.

\subsection{The Analysis of Relationship between BEECT Factors and BELA Variables}

\subsubsection{The Correlation and Multiple Regression Analysis}

Referred to Table 9, the overall condition of BEECT is negatively significantly correlated with BELA $(\mathrm{r}=$ $-0.511, p=0.000)$. The better BEECT environment is, the lower students' BELA is, so are CA $(r=-0.443, p=$ $0.000)$, FNE $(\mathrm{r}=-0.413, p=0.001)$, TA $(\mathrm{r}=-0.366, p=0.004)$, and GA $(\mathrm{r}=-0.522, p=0.000)$. In particular, the factors of CLE $(p=0.000)$ and TSAI $(p=0.001)$ have the negatively significant correlation with BELA and its variables. CLE and TSAI contribute to reducing the anxiety. The factor of SSI $(p=0.003)$ is simply negatively correlated with GA variable, with other BELA variables at the level of little significance.

In general, when communication or interaction between students does not go well, CA or FNE will come into being. On the contrary, if it is smooth, the degree of CA or FNE will be decreased. SSI is concerned with classroom activities, and has no direct relation to the test. The above discussion also accounts for the little significant correlation of TSI to BELA variables. In addition, TSI might bring in the pressure and anxiety especially in communicating the BE specialized or complicated knowledge, or in Q\&A (questions and answers) activities.

In order to get further relationships between BEECT and BELA, multiple regression analysis is necessary to be used to determine to what extent BEECT (independent variables) predict BELA (dependent variable).

In Table 10, Enter method is adopted for this multiple regression analysis to find out the predictive power of every factor of BEECT over BELA.

Multiple $\mathrm{R}=0.727$ indicates that the multiple correlation coefficient between BEECT and BELA is at obviously significant level. $\mathrm{R}$ Square $=0.528$ means that the overall BEECT can account for $52.8 \%$ of variance in BELA, which shows that BELA is determined by BEECT to $52.8 \%$ extent. Sig. F $=0.000$, namely, $p<0.001$ reports that the overall BEECT can significantly interpret and predict BELA.

About the five predictors in Table 10, Beta value means the predictive power of each independent variable. The bigger absolute Beta value of the independent variable is, the stronger predictive power the independent variable has over the dependent variable. Beta value can be positive or negative. Beta value can be positive or negative. Positive Beta value means positive predictive power that the better BEECT is, the more likely BELA is, while negative Beta value means the better BEECT is, the less likely BELA is. The $\mathrm{t}$ - value is used to determine the relative importance of each independent variable; if t-value of an independent variable is more than 2 or less than -2 , namely, $\mathrm{t}>2$ or $\mathrm{t}<-2$, the independent variable will be a useful or significant predictive variable; if $p$-value is less than 0.05 , namely, $p<0.05$, the multiple correlation coefficient is at the significant level.

Table 9. Correlations between BEECT factors and BELA variables.

\begin{tabular}{|c|c|c|c|c|c|c|}
\hline \multicolumn{2}{|c|}{ BEECT Factors and BELA Variables } & \multirow{2}{*}{$\begin{array}{c}\text { Overall anxiety } \\
-0.511\end{array}$} & \multirow{2}{*}{$\begin{array}{c}\text { CA } \\
-0.443\end{array}$} & \multirow{2}{*}{$\begin{array}{c}\text { FNE } \\
-0.413\end{array}$} & \multirow{2}{*}{$\begin{array}{c}\text { TA } \\
-0.366\end{array}$} & \multirow{2}{*}{$\begin{array}{c}\text { GA } \\
-0.522\end{array}$} \\
\hline & Pearson Correlation & & & & & \\
\hline Overall BEECT & Sig. (2-tailed) & 0.000 & 0.000 & 0.001 & 0.004 & 0.000 \\
\hline \multirow{2}{*}{ CLE } & Pearson Correlation & -0.716 & -0.624 & -0.597 & -0.561 & -0.705 \\
\hline & Sig. (2-tailed) & 0.000 & 0.000 & 0.000 & 0.000 & 0.000 \\
\hline \multirow{2}{*}{ TSI } & Pearson Correlation & -0.191 & -0.188 & -0.076 & -0.039 & -0.241 \\
\hline & Sig. (2-tailed) & 0.144 & 0.149 & 0.566 & 0.766 & 0.063 \\
\hline \multirow{2}{*}{ SSI } & Pearson Correlation & -0.319 & -0.246 & -0.218 & -0.246 & -0.374 \\
\hline & Sig. (2-tailed) & 0.013 & 0.058 & 0.095 & 0.059 & 0.003 \\
\hline \multirow{2}{*}{ TSAI } & Pearson Correlation & -0.404 & -0.374 & -0.413 & -0.297 & -0.338 \\
\hline & Sig. (2-tailed) & 0.001 & 0.003 & 0.001 & 0.021 & 0.008 \\
\hline \multirow{2}{*}{ SCL } & Pearson Correlation & -0.120 & -0.062 & -0.137 & -0.140 & -0.128 \\
\hline & Sig. (2-tailed) & 0.361 & 0.635 & 0.297 & 0.287 & 0.330 \\
\hline
\end{tabular}


Table 10. Five factors of BEECT Predicting BELA.

\begin{tabular}{|c|c|c|c|c|}
\hline Dependent Variable & Multiple R & R Square & F-value & Sig.F \\
\hline BELA & $0.727 a$ & 0.528 & 12.089 & 0.000 \\
\hline \multicolumn{5}{|c|}{ Predictors: Five Independent Variables of BEECT } \\
\hline \multicolumn{2}{|c|}{ Independent variables } & Beta & $\mathrm{t}$ & Sig. \\
\hline \multicolumn{2}{|c|}{ CLE } & -0.690 & -6.304 & 0.000 \\
\hline \multicolumn{2}{|c|}{ TSI } & 0.111 & 0.977 & 0.333 \\
\hline \multicolumn{2}{|c|}{ SSI } & -0.010 & -0.079 & 0.937 \\
\hline \multicolumn{2}{|c|}{ TSAI } & -0.132 & -1.100 & 0.276 \\
\hline \multicolumn{2}{|c|}{ SCL } & 0.003 & 0.033 & 0.974 \\
\hline
\end{tabular}

As shown in Table 10, in the five independent variables, only CLE (Beta $=-0.69, \mathrm{t}=-6.304, p=0.000$ ) has negatively significantly predictive power over BELA. The more efficiently students learn BE, the less BELA students can produce; other four predictor are not statistically significant.

\subsubsection{T-Tests of Differences between HSG and LSG}

Independent samples t-tests are adopted to find out the differences between HSG (top 25\% of subjects in BELA) and LSG (bottom 25\% of subjects in BELA) in BEECT.

As Table 11 reports, in BEECT, there are significant differences between HSG and LSG of BELA, especially in CLE ( $p=0.000)$, TSAI $(p=0.007)$, and SSI $(p=0.011)$, which means LSG behave better than HSG in CLE, TSAI, and SSI. The bigger difference is CLE. The differences of TSI and SCL are not at the statistically significant level in that whether the degree of BELA is high or low, in BEECT, all students pay attention to the interaction with the teacher and realize the importance of initiative in BE learning.

The distinct characteristics LSG in this study are listed as follows:

1) LSG are able to master BE teaching content more effectively.

2) LSG are more active in participating in BE teaching activities and answering questions.

3) LSG have little sense of anxiety in BEECT.

4) LSG are more likely to assist the teacher in building a harmonious classroom and optimizing classroom teaching.

5) LSG are more generous and confident in communicating with classmates.

6) LSG are more inclined to keep the harmonious relationship with the teacher, and more willing to have heart-to-heart talks with the teacher, and gain valuable guidance.

\section{Enlightenment on BE Teaching}

\subsection{Cultivating Learners' Academic English Proficiency}

Currently, ESP teaching is carried out in a relatively closed teaching ecology. Without new energy of information, Teaching is usually restricted to the exchange among teachers, teaching materials and students. Learners are good at book knowledge, but they are panic and unaccustomed to the new working circumstances (Kang \& Zhen, 2013: pp. 179-180). Therefore, BE teaching should first foster learners' academic English ability. Cai (2012: pp. 30-35) analyzes the academic needs for English courses, believing that, with the internationalization of Higher Education, learners are crying for academic English, which is the basic communicating medium in professional learning, the common lingual-core for interdisciplinary study, and the true fundamental course serving for professional learning. He also considers the academic English as the sublimated foreign language teaching, advocating the guidance from learner's personal need for foreign language ability to the national level, since what most of the college students need is the ability to communicate academically in English and consult professional literature (Cai, 2014: pp. 3-8).

In order to make the learner communicate successfully with English in business circumstances, teachers should first foster learner's academic English ability. With the content-based approach, teachers can teach the 
Table 11. T-tests of Differences between HSG and LSG of BELA in BEECT.

\begin{tabular}{|c|c|c|c|c|c|}
\hline Independent variables & Group & Mean & $\begin{array}{c}\text { Mean } \\
\text { Difference }\end{array}$ & Std. Error Mean & Sig. (2-tailed) \\
\hline Overall BEECT & $\begin{array}{l}\text { HSG of BELA } \\
\text { LSG of BELA }\end{array}$ & $\begin{array}{l}3.265 \\
3.843\end{array}$ & -0.578 & 0.126 & 0.000 \\
\hline CLE & $\begin{array}{l}\text { HSG of BELA } \\
\text { LSG of BELA }\end{array}$ & $\begin{array}{l}2.750 \\
3.863\end{array}$ & -1.113 & 0.172 & 0.000 \\
\hline TSI & $\begin{array}{l}\text { HSG of BELA } \\
\text { LSG of BELA }\end{array}$ & $\begin{array}{l}3.170 \\
3.527\end{array}$ & -0.357 & 0.180 & 0.056 \\
\hline SSI & $\begin{array}{l}\text { HSG of BELA } \\
\text { LSG of BELA }\end{array}$ & $\begin{array}{l}3.094 \\
3.594\end{array}$ & -0.500 & 0.184 & 0.011 \\
\hline TSAI & $\begin{array}{l}\text { HSG of BELA } \\
\text { LSG of BELA }\end{array}$ & $\begin{array}{l}3.732 \\
4.313\end{array}$ & -0.580 & 0.199 & 0.007 \\
\hline SCL & $\begin{array}{l}\text { HSG of BELA } \\
\text { LSG of BELA }\end{array}$ & $\begin{array}{l}3.938 \\
4.250\end{array}$ & -0.313 & 0.193 & 0.116 \\
\hline
\end{tabular}

business knowledge with the assistance of the really language material. They can compile the BE teaching material in accordance of Chinese learners and cover all the aspects of language specifications, business knowledge and academic competence training. The Teaching activity design should take learner's linguistic ability, knowledge level and thinking ability into consideration. Linguistic knowledge includes academic vocabulary, syntax and discourse structure; the academic ability training contains all the abilities_-listening, speaking, reading and writing-related with academic events.

In BE teaching activities, teachers should also give consideration to the basic components of the EGP language, enhancing learner's fundamental linguistic knowledge and skills. They should also process the EGP resources selectively, paying attention to the consistency between the external linguistic output of BE and internal knowledge of EGP. The unconsciousness of implicit learning is beneficial to BE teaching, stimulating the consciousness privilege of explicit learning, strengthening the learning strategy and reducing learning anxiety so as to enlarge the effect of explicit learning and make the language and skills specialized.

\subsection{Strengthening Learners' Ambiguity Tolerance}

Unfamiliar, vague and complicated linguistic phenomena will result in learner's different feedback and influence their learning outcome (Zhang, 2004: pp. 457-461). Therefore, in the course of BE learning, learners should first clarify the definition of ambiguity tolerance and its application with the assistance of teachers. The teachers should also intervene and regulate emotionally the learners with high or low level of ambiguity tolerance. Comparing with Learners with low level of ambiguity tolerance, learners with high level of ambiguity tolerance are weak in learning anxiety and strong in control and innovation, and they usually succeed in linguistic missions (Wang \& Zhang, 2012: pp. 324-325). Teachers should be tolerant to the learner's mistakes to certain degree and make proper correction to those repeated errors. Zhang (2012: pp. 89-95) believes that intolerance will lead to excessive correction and aggravate the learning anxiety, which is bad for the stimulation on learning strategies, founding correct attitude towards the linguistic ambiguity, and failure in linguistic attempts and speculation.

In addition, teachers should also foster learners ambiguity tolerance in the aspect of BE teaching and learning method. It is necessary for the teachers to know, master and use the proper teaching methods to reduce the learning anxiety, analyze the learner's need and organize flexible teaching activities so as to create ecological learning atmosphere (Li, 2004: pp. 46-51). Also, the teacher should foster learner's trans-cultural ambiguity tolerance in order to understand and practice the culture of the target language better. 


\subsection{Using Ecologically Multimodal Discourses and Building Relaxed and Harmonious BE Learning Atmosphere}

Harmonious learning atmosphere is important for the development of learner's creativity, while undesirable atmosphere will make learners feel depressive and insecure (Huang \& Zou, 2010: pp. 166-167). In other words, in undesirable atmosphere, not only can the learner develop his initiative creativity, but also it will put him on guard. Without the psychologically safe atmosphere, learners will feel anxious. Accordingly, a low pressure, safe and co-adjutant learning atmosphere will be beneficial to the decreasing of learning anxiety and stimulating confidence (Yuan, 2012: pp. 41-45).

Quantity and quality of discourse, questions, feedback, and interactive adjustment—all are playing positive role in building harmonious and sustainable ecological teaching atmosphere (Song, 2013). According to the principle of model state choice given by Zhang (2010: pp. 48-53), whatever way of expression the BE teacher takes, they should adhere to the principle of optimization (i.e. learners should achieve the success of communication by expressing the meaning of discourse to the largest extend), the principle of effective stimulation (i.e. according to the need analysis and learning psychology, teachers should stimulate learner's passion of participation and initiative learning strategies so that the learner can participate in the BE learning activities willingly and transform the external factors into internal factors), and the principle of adaptive coordination (i.e. both the teacher and the learner try their best to build natural ecological BE atmosphere by adapting and coordinating different modes).

Teachers should constantly explore the optimum modal of various discourse factors, insisting on the principle of effective economy and controlling the quantity of discourse. Then, BE will be the " $\mathrm{i}+1$ " comprehensive input, both challenging and acceptable. The teacher should also pay attention to the flexibility of questioning, providing opportunity of two-way communication to learners with different academic levels and summarizing the learner's feedback. In choosing multi-modal discourse, teachers should take full consideration of the academic sectors related with the BE teaching activities (e.g. course content, genre), the adaption of multi-media environment and information technology, the learner's individual situation (i.e. the structure of knowledge, the structure of ability, hobby so on and so forth), the harmonious teacher-student relationship, so as to finally realize the teacher-student interaction physically, emotionally and culturally.

Multimodal ecological discourse (Fan, 2013: pp. 69-72) not only emphasizes the regular logical structure, but also stress on all the life-related natural features: body, emotion, culture, context, media, so on and so forth. With the target of stimulating learner's passion and potential and building harmonious teaching atmosphere, the theory values the teaching environment, learner's talent and cognitive ability, teacher's wisdom and ty .In the interaction among teacher-student emotion, linguistic performance, functional context, cultural integration, teachers can stimulate the learner's original energy, realize the discourse meaning (i.e. conceptual meaning, interpersonal meaning, textual meaning) effectively, expand learner's cognitive range, touch learner's heart and mind, and finally realize the natural connection of teaching.

\section{Limitations of This Study and Suggestions for Further Research}

This study is constrained by time, and personnel so that the sample of subjects, research instruments themselves and their performances are not satisfactory enough to get research results wider and deeper.

Firstly, in this study, the sample is not large enough to represent the holistic state of BELA in China. So, in the future research, BE majors of other colleges or universities will be invited to participate in this study. Secondly, in this study, the questionnaire is used to investigate students' BELA. The results from the questionnaire almost rely on students' sensory responses. The interview should be carried on complementarily so that the results can be adequately realistic and systemized because students are likely to respond subjectively and optionally and even keep back their true ideas. In addition, observation, think-aloud, verbal report or diary should also be needed in the future research.

In spite of limitations of this study, it is expected that this study can shed some light on teaching BE and give some guidance to further study on ESP.

\section{Acknowledgements}

This paper is supported by “ESP Teachers' Classroom Multimodal Discourse Analysis” (No: J15WD50), one of Projects for Humanities and Social Sciences of Scientific Research Development Program for Colleges and Universities in Shandong Province. 


\section{References}

Cai, J. G. (2012). Academic English: Needs Analysis and Teaching Methods. Foreign Language Learning Theory and Practice, No.2, 30-35.

Cai, J. G. (2014). English for Academic Purposes and Quality Foreign Language Education. Computer-Assisted Foreign Language Education, No.157, 3-8.

Chen, H., \& Shan, Y. (2008). An Investigation into Classroom Environment of College English Teaching. Journal of Nanjing University of Aeronautics and Astronautics (Social Sciences), 10, 96-100.

Chen, J. L. (2010). The Integration of Computer and Networks into Foreign Language Teaching-A Research Based on College Teaching Reform. Shanghai: Shanghai Foreign Language Education Press.

Chen, J. L., \& Gu, Z. Z. (2008). More Reasonable and Precise Requirements with Realizing Directions-Interpreting the 2007 College English Curriculum Requirements. Computer-Assisted Foreign Language Education in China, No. 119, 3-8.

Ding, R. L., \& Dai, W. D. (2013). Orientation on College Foreign Language Teaching. Foreign Language Teaching, No. 2, 17-23.

Ellis, R. (1994). The Study of Second Language Acquisition (pp. 34-35). Oxford: Oxford University Press.

Fan, C. X. (2013). The Analysis of Teachers' Ecological Teaching Discourse. University Education Science, No. 6, 69-72.

Gao, L., \& Wang, Z. C. (2010). Anxiety-Causing Factors in Medical English Learning and Strategies to Overcome Them. Northwest Medical Education, No. 1, 138-140.

Gu, Z. Z. (2012). Research on ESP Ecologic Environment-A Case Study at AUFE. Computer-Assisted Foreign Language Education, No. 148, 47-59.

Guo, Jianjing. (2013).Course Design for Constructing ESP Listening \& Speaking English Class Ecology. Journal of Fujian Jiangxia University, No. 4, 99-106.

Horwitz, E. K. \& Horwitz, M. B., \& Cope, J. A. (1986). Foreign Language Classroom Anxiety. Modern Language Journal, 70, 125-132. http://dx.doi.org/10.1111/j.1540-4781.1986.tb05256.x

Huang, Q. W., \& Zou, F. Q. (2010). Research on GIS English Learning Anxiety. Journal of Chifeng University (Soc,Sci), 31, 166-167.

Kang, X. Y., \& Zhen, Y. H. (2013). ESP Research in Educational Ecology. Heilongjiang Researches on Higher Education, No. 8, 179-180.

Kong, F. X. (2012). The Study of Implicit and Explicit Learning on the EGP and ESP. Modern Educational Technology, 22, 74-78.

Leather, J., \& van Dam, J. (2003). Ecology of Language Acquisition. Dordrecht: Springer. http://dx.doi.org/10.1007/978-94-017-0341-3

Lei, S. (2011). The Relationship among Tolerance of Ambiguity, Anxiety and Academic Achievement of Listening Comprehension. Master's Thesis, Wuhan: Hubei University.

Li, J. Y. (2004). Learning Anxiety Analysis from the Perspective of Psychology. Journal of Tianjin Foreign Studies University, 11, 46-51.

Shi, W. N. (2014). Comparison on ESP and EGP Learning Anxiety. Journal of Fuyang Teachers College (Social Science), No. $1,141-143$.

Shi, W. N., \& Gan, Y. N. (2012). Learning Anxiety Based on Stomatology English. Journal of Inner Mongolia University for Nationalities, 18, 225-226.

Song, J. H. (2013). An Empirical Study on Teacher Talk's Functions of College English Teachers from Micro-Educational Ecology Perspective. Master's Thesis, Dalian: Liaoning Normal University.

Sun, Q., \& Wang, L. J. (2013). Oral Expression Anxiety on ESP. Journal of Kaifeng Institute of Education, 33, 90-91.

Wang, H. Y., \& Jia, Y. Q. (2011). Ecological Foreign Language Teaching on Eco-Linguistics. College English Teaching and Research, No. 4, 3-6.

Wang, Y. H., \& Zhang, S. M. (2012). Tolerance of Ambiguity in Second Language Learning. Journal of Juamjusi Education Institute, No. 2, 324-325.

Wen, Q. F. (2014). Competition between ESP and EGP in College English Teaching. Foreign Languages and Their Teaching, No. 1, 1-8.

Wu, J. L. (2014). The Development of ESP in Eco-Linguistics. Intelligence, No. 17, 283-284, 286.

Wu, W. (2011). Ecological Model of Language Teaching. Foreign Language Study, No. 2, 111-122.

Yuan, P. H. (2012). On the Impact of CBI on EFL Learners' Motivation and Anxiety in College English Context. Journal of PLA University of Foreign Language, 35, 41-45. 
Zhang, D. L. (2010). Preliminary Investigation into the Concept of Design and the Selection of Modalities in Multimodal Foreign Language Teaching. Foreign Languages in China, No. 3, 48-53.

Zhang, Q. Z. (2004). Effects of Tolerance of Ambiguity on the Selection of Language Learning Strategies. Foreign Language Teaching and Research (Bimonthly), 36, 457-461.

Zhang, S. M. (2012). Multi-Dimensional Review and Thinking on Tolerance of Ambiguity in 50 Years. Foreign Language World, No. 2, 89-90. 


\section{Appendix 1. Business English Learning Anxiety Scale (BELAS)}

$1=$ "This statement is almost never true of me"

2 = "This statement is usually not true of me"

$3=$ "This statement is sometimes true of me"

$4=$ "This statement is usually true of me"

5 = "This statement is almost always true of me"

1. I never feel quite sure of myself when I am speaking in my BE class.

2. I don't worry about making mistakes in BE class.

3. I tremble when I know that I'm going to be called on in BE class.

4. It frightens me when I don't understand what the teacher is saying in English.

5. It wouldn't bother me at all to take more BE classes.

6. During BE class, I find myself thinking about things that have nothing to do with the course.

7. I keep thinking that the other students are better at BE than I am.

8. I am usually at ease during tests in my BE class.

9. I start to panic when I have to speak without preparation in BE class.

10. I worry about the consequences of failing my BE class.

11. I don't understand why some people get so upset over BE classes.

12. In BE class, I can get so nervous I forget things I know.

13. It embarrasses me to volunteer answers in my BE class.

14. I would not be nervous talking about BE questions with teachers.

15. I get upset when I don't understand what the teacher is correcting.

16. Even if I am well prepared for BE class, I feel anxious about it.

17. I often feel like not going to my BE class.

18. I feel confident when I speak in BE class.

19. I am afraid that my teacher is ready to correct every mistake I make.

20. I can feel my heart pounding when I'm going to be called on in BE class.

21. The more I study for a BE test, the more confused I get.

22. I don't feel pressure to prepare very well for BE class.

23. I always feel that the other students learn BE better than I do.

24. I feel very self-conscious about talking about BE knowledge in front of other students.

25. BE class moves so quickly I worry about getting left behind.

26. I feel more tense and nervous in my BE class than in my other classes.

27. I get nervous and confused when I am speaking in my BE class.

28. When I'm on my way to BE class, I feel very sure and relaxed.

29. I get nervous when I don't understand every word BE teacher says.

30. I feel overwhelmed by the number of specialize words and expressions to learn BE.

31. I am afraid that the other students will laugh at me when I am talking about BE knowledge in English.

32. I would probably feel comfortable around the passages in BE text.

33. I get nervous when the teacher asks questions which I haven’t prepared in advance.

\section{Appendix 2. Questionnaire of Ecological Classroom Teaching of BE (QBEECT)}

$1=$ "This statement is almost never true of me"

2 = "This statement is usually not true of me"

$3=$ "This statement is sometimes true of me"

$4=$ "This statement is usually true of me"

5 = "This statement is almost always true of me"

1. I can master the teaching content of BE course effectively.

2. I can participate in the classroom activities and be active in answering.

3. I am willing to learn BE.

4. I usually willing to learn BE autonomously,

5. I feel little anxious in BE classroom.

6. Students and the teacher can cooperate together to create high-quality BE classroom environment. 
7. Our BE classroom atmosphere is favorable and harmonious.

8. We often have group discussion for BE.

9. BE teacher can discuss questions with us interactively.

10. The teacher often buckets knowledge, in BE classroom, and the group discussion is seldom regularly carried out.

11. More attention and opportunity to perform are often given to excellent students.

12. Whether students' learning achievement is good or not, all students are treated equally without partiality, and offered the similar opportunity to perform.

13. I am more likely to cherish the time and opportunities communication of business English knowledge.

14. In the communication between classmates, I feel inspired and encouraged from other classmates.

15. I participate in the discussion by questioning or putting forward my points of views.

16. I become more confident as a result of the communication between classmates.

17. In the communication between classmates, I can encourage and praise other classmates.

18. I usually feel the way of communication between classmates is effective for BE learning.

19. I usually feel the communication between classmates is a waste of time.

20. I feel BE learning is more interesting through the communication between classmates.

21. The harmonious relationship between the teacher and me is highly better established.

22. The teacher has the strong love and patience of students.

23. The teacher maintains the surrounding with peace and friendship with students.

24. The teacher gives good care to students, and fully respects students.

25. I often get useful advice and help from my conversation with the teacher.

26. The teacher often communicates with students after class, such as how to conduct oneself.

27. The teacher stimulates students' interest in learning fields related to BE.

28. Only if passively learning is transformed into initiatively learning, I would achieve the life-long learning capability.

29. I hold the opinion that the life-long learning capability depends on the teacher's patiently teaching and imparting a lot of knowledge. 